\title{
The Sex Influence on Response to Tumor Necrosis Factor- $\alpha$ Inhibitors and Remission in Axial Spondyloarthritis
}

\author{
Ennio Lubrano, Fabio Massimo Perrotta, Maria Manara, Salvatore D’Angelo, Olga Addimanda, \\ Roberta Ramonda, Leonardo Punzi, Ignazio Olivieri, Carlo Salvarani, and Antonio Marchesoni
}

\begin{abstract}
Objective. The aim of this study was to evaluate the influence of sex on response to treatment and disease remission in patients with axial spondyloarthritis (axSpA).

Methods. In this retrospective multicenter study, patients with axSpA, according to the Assessment of Spondyloarthritis international Society (ASAS) criteria for axSpA, and treated with adalimumab, etanercept, golimumab, or infliximab, were studied. We compared clinical characteristics, patient-reported outcomes, disease activity, function, and response to treatment in male and female patients with this disease.

Results. Three hundred forty patients with axSpA (270 with ankylosing spondylitis, 19 with psoriatic arthritis with axial involvement, and 51 with nonradiographic $\operatorname{axSpA}$ ) were studied. Male subjects had a significantly higher prevalence of grade IV sacroiliitis, higher levels of serum C-reactive protein, lower Maastricht Ankylosing Spondylitis Enthesitis Score, and fatigue when compared with females. Further, Kaplan-Meier survival curves showed that the rate of partial remission, ASAS40 response, and Ankylosing Spondylitis Disease Activity Score (ASDAS) major improvement, but not ASDAS inactive disease, were significantly lower in female patients.

Conclusion. Our data suggest that female sex was associated with a lower rate of response to treatment and of disease remission in patients with axSpA treated with antitumor necrosis factor- $\alpha$ drugs. (First Release November 15 2017; J Rheumatol 2018;45:195-201; doi:10.3899/jrheum.170666)
\end{abstract}

Key Indexing Terms:

SPONDYLOARTHRITIS RESPONSE TO TREATMENT

Spondyloarthritis ( $\mathrm{SpA}$ ) includes a group of chronic inflammatory diseases that affect both the axial and peripheral skeleton. The Assessment of SpondyloArthritis international Society (ASAS) validated classification criteria for axial SpA (axSpA $)^{1}$ include both nonradiographic axSpA (nr-axSpA) and radiographic axSpA or ankylosing spondylitis (AS). Patients with nr-axSpA and AS have comparable, but not identical clinical manifestations and burden of disease:

From the Dipartimento di Medicina e Scienze della Salute "Vincenzo Tiberio," Università degli Studi del Molise, Campobasso; Day Hospital of Rheumatology, Azienda Sistema Socio Sanitario (ASST) Centro

Specialistico Ortopedico Traumatologico G. Pini-Centro Specialistico Traumatologico-Ortopedico (CTO), Milan; Rheumatology Department of Lucania, San Carlo Hospital of Potenza and Madonna delle Grazie Hospital of Matera, Matera; La Struttura Semplice Dipartimentale (SSD) di Medicina e Reumatologia, Istituto Ortopedico Rizzoli, Università di Bologna, Bologna; Rheumatology Unit, Department of Clinical and Experimental Medicine (DIMED), University of Padua, Padua;

Rheumatology Unit, Azienda Ospedaliera-Istituto di Ricovero e Cura a Carattere Scientifico (IRCCS) di Reggio Emilia and Università di Modena e Reggio Emilia, Reggio Emilia, Italy.

Supported by the Gruppo di Studio Spondiloartriti e Artropatia Psoriasica - Antonio Spadaro. All authors are members of this group.

E. Lubrano, MD, PhD, Dipartimento di Medicina e Scienze della Salute "Vincenzo Tiberio," Università degli Studi del Molise; F.M. Perrotta, MD, Dipartimento di Medicina e Scienze della Salute "Vincenzo Tiberio,"

Università degli Studi del Molise; M. Manara, MD, PhD, Day Hospital of studies show ${ }^{2}$ that patients with nr-axSpA have lower presence of magnetic resonance imaging (MRI) lesions, lower prevalence of HLA-B27, and lower levels of C-reactive protein (CRP) compared to patients with AS. Moreover, prevalence of female sex seems to be higher in patients with nr-axSpA. Therefore, some authors argue that nr-axSpA could configure not only the preradiographic stage of AS, but a different disease even within the same umbrella of $\mathrm{SpA}^{2}$.

Personal non-commercial use only. The Journal of Rheumatology Copyright (c) 2018. All rights reserved. 
Finally, no differences were found in response to treatment among AS and $\mathrm{nr}$-axSpA in clinical trials and real-life experiences $^{3,4,5}$. Beyond these differences, in patients with axSpA, growing evidence suggests a different burden of disease and response to treatment between the sexes ${ }^{6,7,8,9}$. Despite different studies that focused their attention on the differences between males and females in $\mathrm{SpA}^{10}$ (i.e., disease activity, functional impairment), to the best of our knowledge, few studies have investigated the possibility of different responses to treatment and different rates of remission among women and men. Because of the availability of effective treatment strategies that can induce a low disease state or remission in patients with axSpA regardless of sex, it would be crucial to know any potential factors that may improve the management of these patients, in the context of a "personalized medicine." The aim of our present study was to assess the possible differences in response to treatment and in disease remission in a group of male and female patients with axSpA.

\section{MATERIALS AND METHODS}

Study design. This was a retrospective study conducted in 6 Italian tertiary referral rheumatology centers involved in clinical research and management of axSpA. In our clinical practice, data of patients with axSpA taking biologics were regularly collected at each visit. Patients provided their written consent according to the Declaration of Helsinki to use their data. Ethics approval was not required for this study in accordance with the policy of our institution (Università degli Studi del Molise).

Patient selection. The data were analyzed of patients with axSpA who fulfilled the ASAS criteria for axSpA and were treated with a first anti-tumor necrosis factor (TNF) drug such as adalimumab (ADA), etanercept (ETN), infliximab (IFX), and golimumab (GOL) between June 2004 and May 2015 and with a followup of at least 12 months. At baseline (prior to starting anti-TNF) and at each followup visit, demographic, disease activity, laboratory, and radiographic features were collected.

Therapy. Anti-TNF- $\alpha$ drugs were given following the standard administration rules. More precisely, ADA dose was $40 \mathrm{mg}$ every other week subcutaneously, ETN $25 \mathrm{mg}$ twice/weekly or $50 \mathrm{mg} /$ weekly subcutaneously, and IFX $3-5 \mathrm{mg} / \mathrm{kg}$ at weeks 0,2 , and 6 , then every $6-8$ weeks, intravenously. The treating physician, however, could increase or decrease doses or change schedule when warranted. GOL doses were $50 \mathrm{mg}$ or $100 \mathrm{mg}$ monthly subcutaneously for patients with weight of $<100 \mathrm{~kg}$ or $\geq 100 \mathrm{~kg}$, respectively.

Data collection. Patient data were collected at baseline and at the followup visits, which were usually performed every $3-4$ months. The general data included age, sex, diagnosis [nr-axSpA, psoriatic arthritis (PsA) with axial involvement fulfilling the ASAS criteria, and AS], disease duration, presence of extraarticular manifestations (i.e., uveitis, inflammatory bowel diseases, psoriasis), and current comorbidities. The disease data encompassed the Bath AS Metrology Index (BASMI) $)^{11}$, Bath AS Disease Activity Index (BASDAI $^{12}$, Bath AS Functional Index (BASFI) ${ }^{13}$, Ankylosing Spondylitis Disease Activity Score (ASDAS) ${ }^{14}$, patient's global disease activity on a 0-100 mm visual analog scale (VAS), physician's global disease activity on a 0-100 mm VAS, number of swollen (out of 66) and tender (out of 68) joints, presence of dactylitis and enthesitis [assessed with the Maastricht Ankylosing Spondylitis Enthesitis Score (MASES)], degree of radiographic sacroiliitis according to the New York criteria ${ }^{15}$, erythrocyte sedimentation rate $(\mathrm{mm} / \mathrm{h})$, and $\mathrm{CRP}(\mathrm{mg} / \mathrm{dl})$.

The discontinuation reasons were classified as inefficacy, adverse events, or other reasons. Details were also recorded of past (before anti-TNF- $\alpha$ therapy) and current antirheumatic treatments, such as synthetic disease-modifying antirheumatic drugs, corticosteroids, nonsteroidal antiinflammatory drugs, or analgesics.

Definition of response to treatment and remission. Response to treatment was assessed at followup visits using the ASAS $40 \%$ response criteria and ASDAS-CRP major improvement (ASDAS MI) ${ }^{16,17}$. Improvement of $\geq 2$ from baseline in the ASDAS-CRP identified the ASDAS MI. Remission was defined using the ASAS partial remission (PR) criteria and with the ASDAS-CRP inactive disease (ASDAS ID). An ASDAS score $<1.3$ defined the inactive disease ${ }^{16,17}$. The ASDAS was calculated using an online calculator (www.asas-group.org). To perform our analysis, we used the data of patients when they reached PR, ASAS40, ASDAS ID, and ASDAS MI. For patients who never achieved the target, data of the latest followup were used.

Statistical analysis. After testing for normal distribution of data, descriptive results were reported as mean (SD) or median [interquartile range (IQR)] values for continuous variables, or number (percentages) for categorical ones.

For continuous variables, the significance of the differences between male and female patients was determined using the Student's t test for unpaired data for variables normally distributed and the Mann-Whitney U test for unpaired samples for non-normally distributed variables. Categorical variables were compared by the chi-square test or Fisher's exact test.

The probability of achieving response to treatment or remission in male or in female patients was analyzed using both univariate and multivariate analysis (logistic regression analysis).

Kaplan-Meier (KM) curves were plotted to determine the rates of PR, ASAS40, ASDAS MI, and ASDAS ID during treatment with ADA, ETN, IFX, or GOL. In KM curves calculation, we entered time until the subject was "censored" or the "event" occurred. The differences between curves were determined by the log-rank (Mantel-Cox) test. All the statistical tests were 2-sided at the 5\% level and performed using SPSS software (version 17.0; SPSS Inc.).

\section{RESULTS}

From June 2004 to May 2015,340 patients with axSpA were treated with first-line IFX, ADA, GOL, and ETN (270 with AS, 19 PsA with axial involvement, and 51 with nr-axSpA). The male:female ratio was 236:104. Mean (SD) age was 43.2 years (12.7), and median (IQR) disease duration was 7 years (3-14). Table 1 shows the demographic, clinical, and laboratory features of this group of patients. Overall rate of drug discontinuation during followup was $8.2 \%$ owing to lack of efficacy, loss of efficacy, and other reasons (data not shown). In our group of patients with SpA, male subjects had a significantly higher prevalence of grade IV sacroiliitis, higher levels of serum CRP, lower VAS fatigue score, and lower MASES score when compared with female subjects. Disease activity indices (BASDAI and ASDAS-CRP) and functional domains (BASFI, Health Assessment Questionnaire) were not statistically different between the 2 groups at baseline. Analysis of differences between female and male in the reasons for discontinuation of the treatment showed no significant differences. Extraarticular manifestations as well as the presence of smoking habit, obesity, and comorbidities were not different between the 2 sexes. Further, KM survival curves showed that the rates of PR, ASAS40 response, and ASDAS MI, but not ASDAS ID during treatment with anti-TNF were significantly lower in women (Figure 1, Figure 2, Figure 3, and Figure 4, Appendix 1). Table 2 shows the probability (OR, 95\% CI) of achieving response to

Personal non-commercial use only. The Journal of Rheumatology Copyright @ 2018. All rights reserved. 
Table 1. Demographic, clinical, and radiographic characteristics of male and female patients with axSpA. Data are median (IQR) unless otherwise indicated.

\begin{tabular}{|c|c|c|c|}
\hline Characteristics & Male, $n=236$ & Female, $n=104$ & $\mathrm{p}$ \\
\hline Age, yrs, mean (SD) & $44.34(12.5)$ & $46.12(12.71)$ & 0.22 \\
\hline Disease duration, mos & $84(36-180)$ & $72(23-151)$ & 0.15 \\
\hline Grade IV sacroiliitis, n (\%) & $68(28.5)$ & $14(13.7)$ & 0.003 \\
\hline Hip/shoulder involvement, $\mathrm{n}(\%)$ & $54(22.6)$ & $20(19.6)$ & 0.66 \\
\hline BMI & $25.8(22.3-29.6)$ & $26.6(23.1-29.7)$ & 0.13 \\
\hline Smoking, current, n (\%) & $90(38.1)$ & $32(30.7)$ & 0.22 \\
\hline \multicolumn{4}{|c|}{$\begin{array}{l}\text { Other comorbidities (hypertension, } \\
\text { hypercholesterolemia, diabetes mellitus type II, }\end{array}$} \\
\hline cardiovascular diseases), n (\%) & $62(26.2)$ & $31(29.8)$ & 0.51 \\
\hline Extraarticular manifestation, $\mathrm{n}(\%)$ & $81(34.0)$ & $34(33.3)$ & 0.54 \\
\hline HLA-B27+ $(\%)$ & 65.5 & 55.5 & 0.34 \\
\hline $\mathrm{PtGA}, \mathrm{cm}$ & $6.8(5.3-8)$ & $7.1(5.8-8)$ & 0.63 \\
\hline VAS spinal pain, $\mathrm{cm}$ & $7(5-8.7)$ & $7.5(6-9.1)$ & 0.26 \\
\hline VAS fatigue, $\mathrm{cm}$ & $6.1(5-8.2)$ & $7.3(5.9-8.9)$ & 0.01 \\
\hline VAS morning stiffness & $6(5-9.2)$ & $6.4(5-9)$ & 0.86 \\
\hline BASDAI & $5.7(4.8-7.4)$ & $6.1(5.1-7.52)$ & 0.13 \\
\hline BASMI & $3(2-4)$ & $3(1.5-4)$ & 0.17 \\
\hline BASFI & $5.5(4-7.5)$ & $5.5(4.4-7.1)$ & 0.79 \\
\hline ASDAS-CRP & $3.7(2.9-4.1)$ & $3.4(2.3-4)$ & 0.08 \\
\hline $\mathrm{CRP}, \mathrm{mg} / \mathrm{dl}$ & $1.3(0.8-2.5)$ & $1(0.5-1.9)$ & 0.01 \\
\hline HAQ & $1(0.62-1.37)$ & $1(0.75-1.5)$ & 0.31 \\
\hline MASES & $0(0-2)$ & $1(0-3)$ & 0.02 \\
\hline \multicolumn{4}{|l|}{ Anti-TNF } \\
\hline $\mathrm{ADA}, \mathrm{n}=62$ & $42(17.7)$ & $20(19.6)$ & 0.64 \\
\hline ETN, $\mathrm{n}=96$ & $68(28.6)$ & $28(27.4)$ & 0.13 \\
\hline IFX, $\mathrm{n}=173$ & $120(50.4)$ & $53(52)$ & 0.55 \\
\hline $\mathrm{GOL}, \mathrm{n}=9$ & $6(2.5)$ & $3(2.9)$ & 0.89 \\
\hline AS & 198 & 72 & 0.003 \\
\hline nr-axSpA & 30 & 21 & 0.09 \\
\hline Axial PsA & 8 & 11 & 0.5 \\
\hline
\end{tabular}

Data in bold face are statistically significant. IQR: interquartile range; BMI: body mass index; PtGA: patient's global assessment; VAS: visual analog scale; BASDAI: Bath Ankylosing Spondylitis Disease Activity Index; BASMI: Bath Ankylosing Spondylitis Metrology Index; BASFI: Bath Ankylosing Spondylitis Functional Index; ASDAS: Ankylosing Spondylitis Disease Activity Score; CRP: C-reactive protein; HAQ: Health Assessment Questionnaire; MASES: Maastricht Ankylosing Spondylitis Enthesitis Score; TNF: tumor necrosis factor; ADA: adalimumab; ETN: etanercept; IFX: infliximab; GOL: golimumab, AS: ankylosing spondylitis; SpA: spondyloarthritis; nr-axSpA: nonradiographic axial SpA; PsA: psoriatic arthritis.

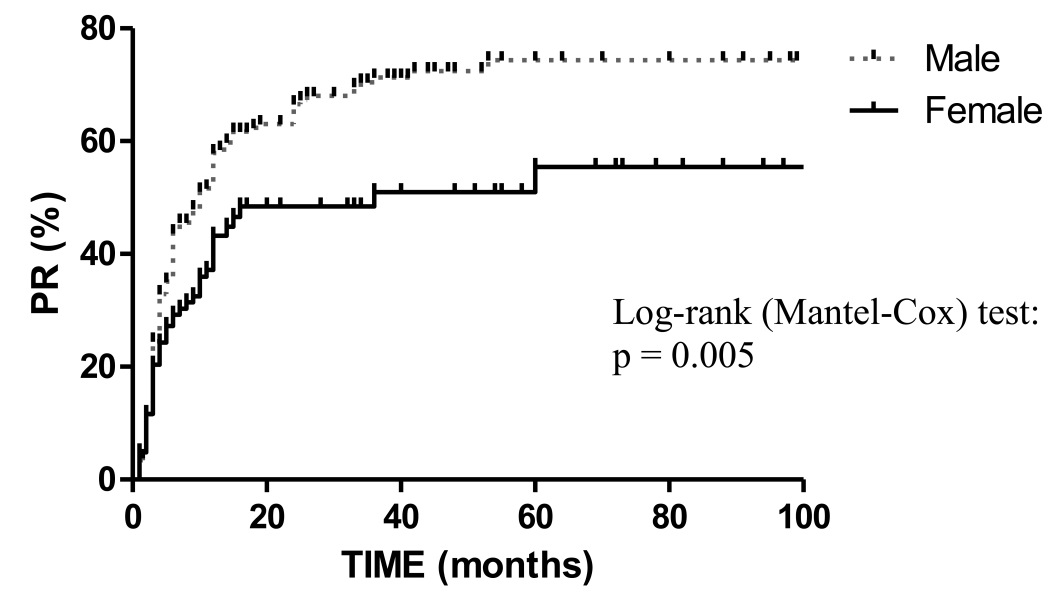

Figure 1. Kaplan-Meier survival curves for partial remission (PR) during treatment with biologic agents in male and female patients with axial spondyloarthritis. 


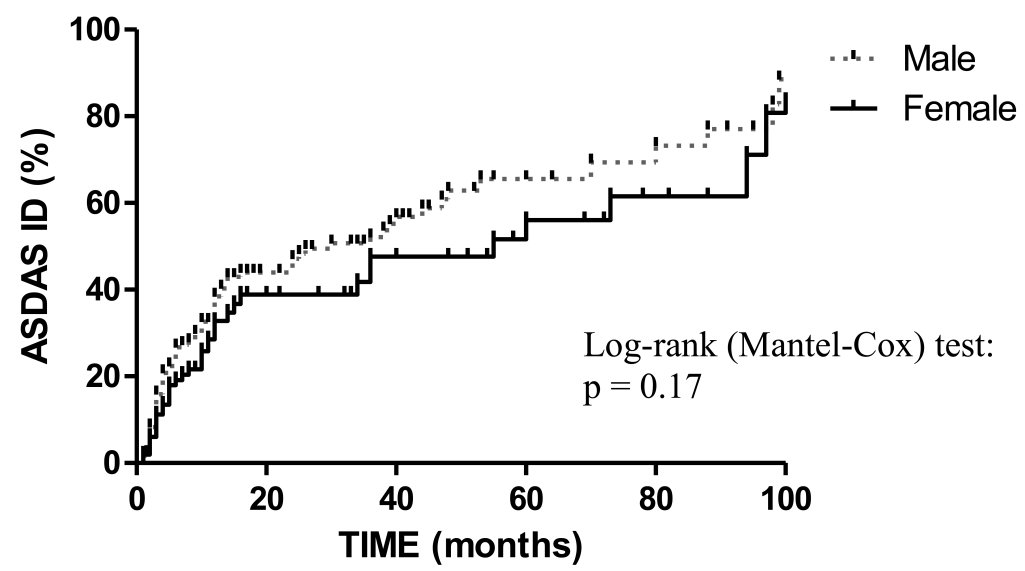

Figure 2. Kaplan-Meier survival curves for Ankylosing Spondylitis Disease Activity Score (ASDAS) inactive disease (ID) during treatment with biologic agents in male and female patients with axial spondyloarthritis.

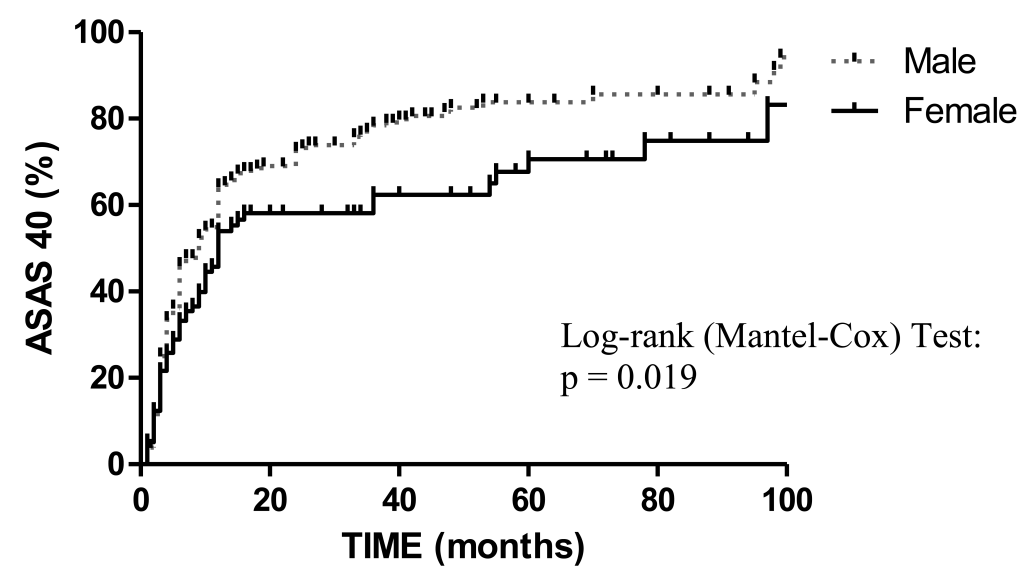

Figure 3. Kaplan-Meier survival curves for Assessment of Spondyloarthritis international Society guidelines (ASAS40) response during treatment with biologic agents in male and female patients with axial spondyloarthritis.

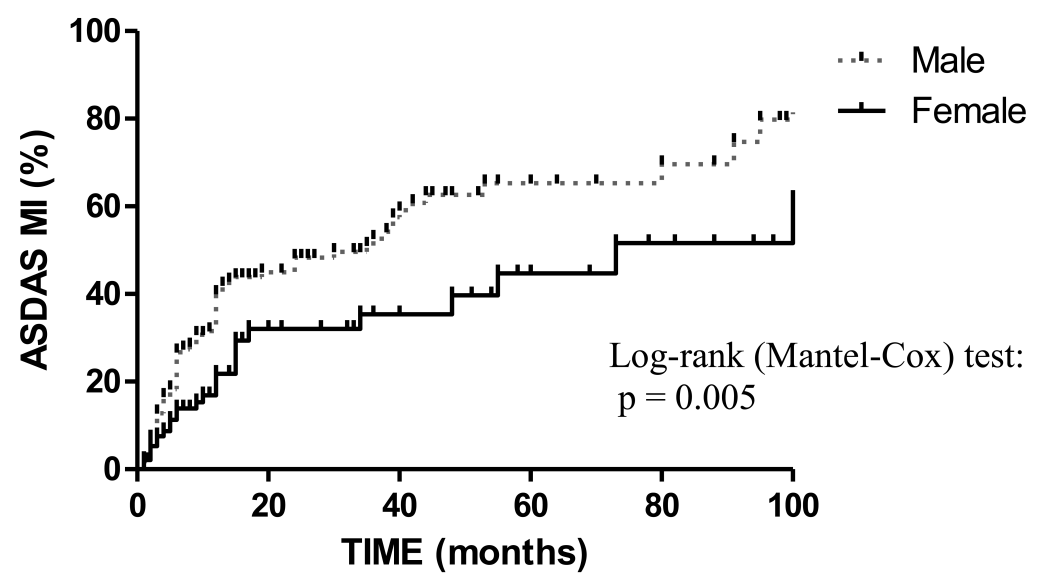

Figure 4. Kaplan-Meier survival curves for Ankylosing Spondylitis Disease Activity Score (ASDAS) major improvement (MI) during treatment with biologic agents in male and female patients with axial spondyloarthritis. 
Table 2. OR (95\% CI) for achieving PR, ASDAS ID, ASAS40, and ASDAS MI in male patients vs female patients with axSpA.

\begin{tabular}{lcccc}
\hline Variables & Univariate Analysis & Multivariate Analysis \\
& Male vs Female OR (95\% CI) & p & Male vs Female OR (95\% CI) & $\mathrm{p}$ \\
\hline PR & $2.219(1.412-3.486)$ & $<0.01$ & $3.071(1.587-5.943)$ & $<0.01$ \\
ASDAS ID & $1.120(0.6988-1.796)$ & 0.8 & $1.454(0.763-2.771)$ & 0.25 \\
ASAS40 & $2.023(1.206-3.394)$ & $<0.01$ & $3.162(1.598-6.295)$ & $<0.01$ \\
ASDAS MI & $1.704(1.039-2.795)$ & 0.03 & $1.913(1.133-3.231)$ & 0.015 \\
\hline
\end{tabular}

PR: partial remission; ASDAS ID: Ankylosing Spondylitis Disease Activity Score inactive disease; ASAS40: Assessment of SpondyloArthritis international Society, 40\% of response; ASDAS MI: Ankylosing Spondylitis Disease Activity Score major improvement; axSpA: axial spondyloarthritis.

treatment or disease remission in male and in female patients. Men had a 2-fold increase in probability to achieve PR compared to women.

Finally, the strength of agreement between PR and ASDAS ID was fair: Cohen's $\kappa=0.23$, showing that the 2 measures might assess remission in different ways.

\section{DISCUSSION}

The introduction and use of anti-TNF therapies for the treatment of several rheumatic diseases has been one of the most important therapeutic innovations in rheumatology in the past 20 years. These drugs proved to be effective in the treatment of axSpA in clinical trials and real-life experiences ${ }^{18,19,20,21}$. With the availability of effective drugs, research interests have focused on potential clinical variables and biomarkers able to identify the best responders to these drugs.

The issue of the patient's sex has become clear in rheumatoid arthritis, where several studies provided evidence that men respond better to treatment than women ${ }^{22,23}$. There is an ongoing debate in the fields of axSpA regarding the different disease expression in relation to sex. The differences could be due to sex (i.e., genetic, hormonal, other phenotypic differences) or gender, which comprises culture-related differences in physical activity, diagnosis, environmental influences, infections, smoking, and other factors, or a combination of both. Data provided from clinical studies revealed that regarding overall radiographic severity, women with AS tend to have less radiographic spinal damage compared to men $^{24,25}$

In axSpA as a group, a recent study of a cohort with early disease $^{9}$ showed that women had higher disease activity when measured with BASDAI and higher levels of fatigue and functional scores, despite having less radiographic sacroiliitis and MRI inflammation of sacroiliac joints and spine than men. However, when measured with the ASDAS-CRP, disease activity was not different between men and women. These differences were more defined in the patients with axSpA classified according to the clinical arm of the ASAS criteria ${ }^{9}$, while in the patients with imaging-positive axSpA, disease activity and functional scores did not differ between women and men, except for fatigue and for the Ankylosing Spondylitis Quality of Life questionnaire (ASQoL). A more recent study involving patients with SpA showed that, overall, male patients were significantly younger, had longer diagnostic delay, lower disease activity (BASDAI), and better quality of life (ASQoL), but worse spinal mobility (BASMI) and higher radiologic score (BASRI) than female patients. In contrast, the presence of dactylitis and enthesitis, as well as the number of swollen joints, were significantly higher among women ${ }^{6}$. Similar data were observed in 1514 patients from the Spanish SpA Registry (REGISPONSER) ${ }^{8}$, as well as in a study conducted in the United Kingdom ${ }^{26}$.

The differences in the MASES score seen in our study and the overall higher scores in disease activity, pain, and quality of life demonstrated by other studies might be due to the presence of fibromyalgia (FM), which may be a confounding factor, especially in women with axSpA ${ }^{5}$. The clinical features of FM and axSpA, such as fatigue, enthesitis, tender points, and intensity of axial and peripheral pain, could overlap. Further, in women, FM is frequently associated with $\mathrm{AS}^{27}$. These findings raise the question of whether patients, in particular women, classified as having axSpA by the clinical arm of ASAS criteria, might be misclassified. Debate continues over whether the ASAS classification criteria should be modified to increase their specificity ${ }^{28}$, even if the positive predictive value of the criteria to predict the expert's diagnosis of SpA after more than 4 years has been found to be excellent ${ }^{29}$.

Our study also revealed differences in treatment response and remission rates between men and women in patients with axSpA treated with biologics. There are a few reports that address this topic. Gremese, et $a l^{30}$ demonstrated that female sex was associated with a lower rate of response (assessed by BASDAI50) in patients with axSpA who were treated with anti-TNF drugs. In particular, female sex was an independent predictor of a failure to obtain a BASDAI50 response at the 12th month of therapy, with an OR of 3.23 (95\% CI $1.52-7.14)^{30}$. Other studies confirmed that women have a lower response to anti-TNF compared to men and have a higher risk of discontinuation of TNF blockers ${ }^{31,32}$. Another

Personal non-commercial use only. The Journal of Rheumatology Copyright @) 2018. All rights reserved. 
study in patients with AS showed that female sex was a negative predictor of response to IFX, along with use of steroids, persistently high inflammatory levels, and BASFI and BASDAI indices ${ }^{31}$. In a metaanalysis, data suggested that male sex together with young age, high BASDAI, low BASFI, high CRP, and HLA-B27 are factors linked to better response to anti-TNF in $\mathrm{SpA}^{33}$.

In our retrospective study, we confirmed these data and showed that even the probability of achieving remission is lower in female patients (Table 2). However, the probability is significantly lower in female patients only when remission was assessed with the PR criteria, while it was not significantly different when remission was defined using the ASDAS ID criteria. Why was the probability of achieving PR different between men and women while the probability of achieving ASDAS ID was not, and further, why were there sex differences in ASDAS MI and not in ASDAS ID? One may think that the question is related to the different methods in the assessment of disease activity, but these results need further confirmation. One of the reasons could be that the ASDAS MI measures a difference $(\Delta)$ in disease activity, showing an ability to detect the sensitivity to change, while ASDAS ID is a "picture" of disease status. However, given this methodological explanation, it is very difficult to find a reason for this difference obtained when analyzed by sex. In our study, the presence of obesity and extraarticular manifestations did not have a role in achieving remission between the sexes. However, even if some cardiovascular comorbidities such as aortic involvement in $\mathrm{SpA}^{34}$ or atherosclerosis are quite common ${ }^{35}$, to our knowledge no data on comorbidities assessed by sex have been previously described.

Further longitudinal studies are required to assess the genetic background of sex differences in disease expression, especially in multiethnic cohorts. In fact, in our study $>95 \%$ of patients were white, and confounding factors such as ethnicity should be taken into account. Other limitations of our study were the retrospective design and the lack of MRI assessment in all of the patients. However, while MRI assessment is important to define the diagnosis of nr-axSpA, it is not part of routine assessment in our outpatient clinics for patients with AS. Despite these limitations, our study provided data from a large cohort of patients with axSpA and showed that male and female patients affected by axSpA had different responses to anti-TNF therapy.

\section{REFERENCES}

1. Rudwaleit M, van der Heijde D, Landewé R, Listing J, Akkoc N, Brandt J, et al. The development of Assessment of SpondyloArthritis international Society classification criteria for axial spondyloarthritis (part II): validation and final selection. Ann Rheum Dis 2009;68:777-83

2. Baraliakos X, Braun J. Non-radiographic axial spondyloarthritis and ankylosing spondylitis: what are the similarities and differences? RMD Open 2015;1 Suppl 1:e000053.

3. Lubrano E, Perrotta FM, Marchesoni A, D'Angelo S, Ramonda R,
Addimanda $\mathrm{O}$, et al. Remission in nonradiographic axial spondyloarthritis treated with anti-tumor necrosis factor- $\alpha$ drugs: an Italian multicenter study. J Rheumatol 2015;42:258-63.

4. Sieper J, Lenaerts J, Wollenhaupt J, Rudwaleit M, Mazurov VI, Myasoutova L, et al. Efficacy and safety of infliximab plus naproxen versus naproxen alone in patients with early, active axial spondyloarthritis: results from the double-blind, placebo-controlled INFAST study, Part 1. Ann Rheum Dis 2014;73:101-7.

5. Song IH, Weiß A, Hermann KG, Haibel H, Althoff CE, Poddubnyy $\mathrm{D}$, et al. Similar response rates in patients with ankylosing spondylitis and non-radiographic axial spondyloarthritis after 1 year of treatment with etanercept: results from the ESTHER trial. Ann Rheum Dis 2013;72:823-5.

6. Landi M, Maldonado-Ficco H, Perez-Alamino R, Maldonado-Cocco JA, Citera G, Arturi P, et al. RESPONDIA Group. Gender differences among patients with primary ankylosing spondylitis and spondylitis associated with psoriasis and inflammatory bowel disease in an iberoamerican spondyloarthritis cohort. Medicine 2016;95:e5652.

7. Arends S, Brouwer E, van der Veer E, Groen H, Leijsma MK, Houtman PM, et al. Baseline predictors of response and discontinuation of tumor necrosis factor-alpha blocking therapy in ankylosing spondylitis: a prospective longitudinal observational cohort study. Arthritis Res Ther 2011;13:R94.

8. Ortega Castro R, Font Ugalde P, Castro Villegas MC, Calvo Gutiérrez J, Muñoz Gomariz E, Zarco Montejo P, et al. Different clinical expression of patients with ankylosing spondylitis according to gender in relation to time since onset of disease. Data from REGISPONSER. Reumatol Clin 2013;9:221-5.

9. Tournadre A, Pereira B, Lhoste A, Dubost JJ, Ristori JM, Claudepierre P, et al. Differences between women and men with recent-onset axial spondyloarthritis: results from a prospective multicenter French cohort. Arthritis Care Res 2013;65:1482-9.

10. Nas K, Capkin E, Dagli AZ, Cevik R, Kilic E, Kilic G, et al. Anatolian Group for the Assessment in Rheumatic Diseases (ANGARD). Gender specific differences in patients with psoriatic arthritis. Mod Rheumatol 2017;27:345-9.

11. Jenkinson TR, Mallorie PA, Whitelock HC, Kennedy LG, Garret SL, Calin A. Defining spinal mobility in ankylosing spondylitis (AS). The Bath AS Metrology Index. J Rheumatol 1994;21:1694-8.

12. Garret S, Jenkinson T, Whitelock H, Gaisford P, Calin A. A new approach to defining disease status in ankylosing spondylitis: the Bath Ankylosing spondylitis Activity Index. J Rheumatol 1994;21:2286-91.

13. Calin A, Garrett S, Whitelock H, Kennedy LG, O'Hea J, Mallorie P, et al. A new approach to defining functional ability in ankylosing spondylitis: the development of the Bath Ankylosing Spondylitis Functional Index. J Rheumatol 1994;21:2281-5.

14. Lukas C, Landewé R, Sieper J, Dougados M, Davis J, Braun J, et al; Assessment of SpondyloArthritis international Society. Development of an ASAS-endorsed disease activity score (ASDAS) in patients with ankylosing spondylitis. Ann Rheum Dis 2009;68:18-24

15. Van der Linden S, Valkenburg HA, Cats A. Evaluation of diagnostic criteria for ankylosing spondylitis. A proposal for modification of the New York criteria. Arthritis Rheum 1984;27:361-8.

16. Anderson JJ, Baron G, van der Heijde D, Felson DT, Dougados M. Ankylosing spondylitis assessment group preliminary definition of short-term improvement in ankylosing spondylitis. Arthritis Rheum 2001;44:1876-86.

17. Machado P, Landewé R, Lie E, Kvien TK, Braun J, Baker D, et al. Assessment of SpondyloArthritis international Society. Ankylosing Spondylitis Disease Activity Score (ASDAS): defining cut-off values for disease activity states and improvement scores. Ann Rheum Dis 2011;70:47-53. 
18. Sieper J, van der Heijde D, Dougados M, Mease PJ, Maksymowych WP, Brown MA, et al. Efficacy and safety of adalimumab in patients with non-radiographic axial spondyloarthritis: results of a randomized placebo-controlled trial (ABILITY-1). Ann Rheum Dis 2013;72:815-22.

19. Spadaro A, Lubrano E, Marchesoni A, D'Angelo S, Ramonda R, Addimanda $\mathrm{O}$, et al. Remission in ankylosing spondylitis treated with anti-TNF- $\alpha$ drugs: a national multicentre study. Rheumatology 2013;52:1914-9.

20. Landewé R, Braun J, Deodhar A, Dougados M, Maksymowych WP, Mease PJ, et al. Efficacy of certolizumab pegol on signs and symptoms of axial spondyloarthritis including ankylosing spondylitis: 24-week results of a double-blind randomised placebo-controlled Phase 3 study. Ann Rheum Dis 2014;73:39-47.

21. Sepriano A, Regel A, van der Heijde D, Braun J, Baraliakos X, Landewé R, et al. Efficacy and safety of biological and targeted-synthetic DMARDs: a systematic literature review informing the 2016 update of the ASAS/EULAR recommendations for the management of axial spondyloarthritis. RMD Open 2017;3:e000396

22. Jawaheer D, Maranian P, Park G, Lahiff M, Amjadi SS, Paulus HE. Disease progression and treatment responses in a prospective DMARD naive seropositive early rheumatoid arthritis cohort: does gender matter? J Rheumatol 2010;37:2475-85.

23. Forslind K, Hafström I, Ahlmén M, Svensson B; BARFOT Study Group. Sex: a major predictor of remission in early rheumatoid arthritis? Ann Rheum Dis 2007;66:46-52.

24. Lee W, Reveille JD, Davis JC Jr, Learch TJ, Ward MM, Weisman $\mathrm{MH}$. Are there gender differences in the severity of ankylosing spondylitis? Results from the PSOAS cohort. Ann Rheum Dis 2007;66:633-8.

25. Lee W, Reveille JD, Weisman MH. Women with ankylosing spondylitis: a review. Arthritis Rheum. 2008;59:449-54.

26. Roussou E, Sultana S. Spondyloarthritis in women: differences in disease onset, clinical presentation, and Bath Ankylosing
Spondylitis Disease Activity and Functional indices (BASDAI and BASFI) between men and women with spondyloarthritides. Clin Rheumatol 2011;30:121-7.

27. Aloush V, Ablin JN, Reitblat T, Caspi D, Elkayam O. Fibromyalgia in women with ankylosing spondylitis. Rheumatol Int 2007 ; 27:865-8.

28. Deodhar A, Strand V, Kay J, Braun J. The term 'non-radiographic axial spondyloarthritis' is much more important to classify than to diagnose patients with axial spondyloarthritis. Ann Rheum Dis 2016;75:791-4

29. Sepriano A, Landewé R, van der Heijde D, Sieper J, Akkoc N Brandt J. Predictive validity of the ASAS classification criteria for axial and peripheral spondyloarthritis after follow-up in the ASAS cohort: a final analysis. Ann Rheum Dis 2016;75:1034-42.

30. Gremese E, Bernardi S, Bonazza S, Nowik M, Peluso G, Massara A, et al. Body weight, gender and response to TNF- $\alpha$ blockers in axial spondyloarthritis. Rheumatology 2014;53:875-81.

31. Lorenzin M, Ortolan A, Frallonardo P, Oliviero F, Punzi L, Ramonda R. Predictors of response and drug survival in ankylosing spondylitis patients treated with infliximab. BMC Musculoskelet Disord 2015;16:166.

32. Favalli EG, Selmi C, Becciolini A, Biggioggero M, Ariani A, Santilli D, et al. Eight-year retention rate of first-line tumor necrosis factor inhibitors in spondyloarthritis: A multi-center retrospective analysis. Arthritis Care Res 2017;69:867-74.

33. Maneiro JR, Souto A, Salgado E, Mera A, Gomez-Reino JJ Predictors of response to TNF antagonists in patients with ankylosing spondylitis and psoriatic arthritis: systematic review and meta-analysis. RMD Open 2015;1:e000017.

34. Palazzi C, D'Angelo S, Lubrano E, Olivieri I. Aortic involvement in ankylosing spondylitis. Clin Exp Rheumatol 2008;26 Suppl 49:S131-4.

35. Hamdi W, Chelli Bouaziz M, Zouch I, Ghannouchi MM, Haouel M, Ladeb MF, et al. Assessment of preclinical atherosclerosis in patients with ankylosing spondylitis. J Rheumatol 2012;39:322-6.

APPENDIX 1. Kaplan-Meier survival curves for partial remission (PR) during treatment with biologic agents in male and female patients with nonradiographic axial spondyloarthritis $(n=51)$.

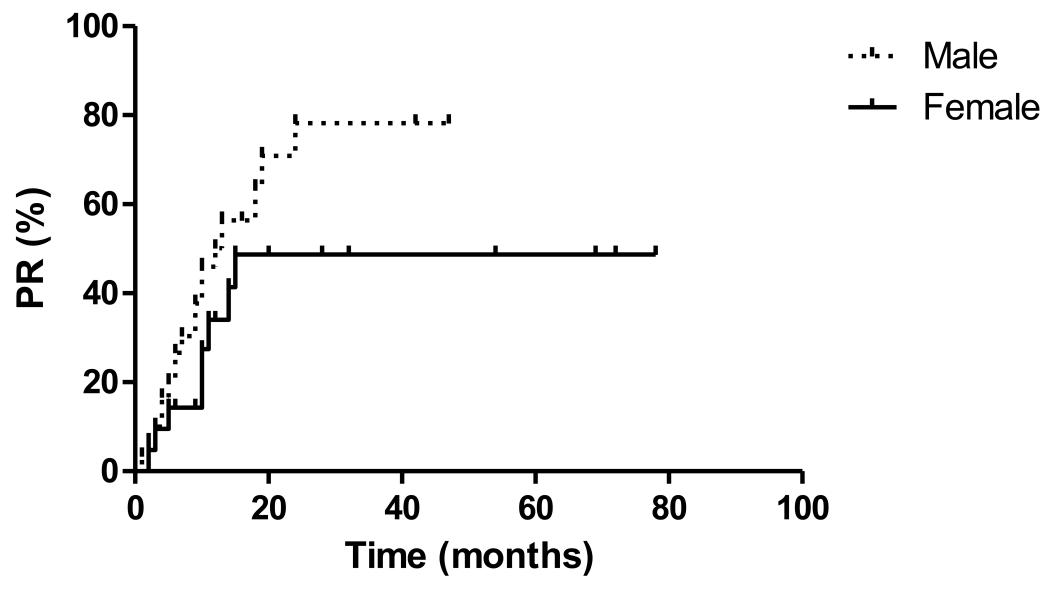

Log-rank (Mantel-Cox) test: $p=0.1$ 